\title{
An Update on Pharmacological, Pharmacokinetic Properties and Drug-Drug Interactions of Rotigotine Transdermal System in Parkinson's Disease and Restless Legs Syndrome
}

\author{
Jan-Peer Elshoff $^{1} \cdot$ Willi Cawello $^{1} \cdot$ Jens-Otto Andreas $^{1} \cdot$ Francois-Xavier Mathy $^{2}$ • \\ Marina Braun ${ }^{1}$
}

Published online: 21 March 2015

(C) The Author(s) 2015. This article is published with open access at Springerlink.com

\begin{abstract}
This narrative review reports on the pharmacological and pharmacokinetic properties of rotigotine, a non-ergolinic $\mathrm{D}_{3} / \mathrm{D}_{2} / \mathrm{D}_{1}$ dopamine receptor agonist approved for the treatment of early- and advanced-stage Parkinson's disease (PD) and moderate to severe restless legs syndrome (RLS). Rotigotine is formulated as a transdermal patch providing continuous drug delivery over $24 \mathrm{~h}$, with a plasma concentration profile similar to that of administration via continuous intravenous infusion. Absolute bioavailability after $24 \mathrm{~h}$ transdermal delivery is $37 \%$ of the applied rotigotine dose. Following a single administration of rotigotine transdermal system (24-h patch-on period), most of the absorbed drug is eliminated in urine and feces as sulphated and glucuronidated conjugates within $24 \mathrm{~h}$ of patch removal. The drug shows a high apparent volume of distribution $(>2500 \mathrm{~L}$ ) and a total body clearance of 300-600 L/h. Rotigotine transdermal system provides dose-proportional pharmacokinetics up to supratherapeutic dose rates of $24 \mathrm{mg} / 24 \mathrm{~h}$, with steadystate plasma drug concentrations attained within 1-2 days of daily dosing. The pharmacokinetics of rotigotine transdermal patch are similar in healthy subjects, patients with early- or advanced-stage PD, and patients with RLS when comparing dose-normalized area under the plasma con-
\end{abstract}

Jan-Peer Elshoff

Jan-Peer.Elshoff@ucb.com

1 UCB Pharma, Alfred-Nobel-Strasse 10, 40789

Monheim am Rhein, Germany

2 UCB Pharma, Braine 1‘Alleud, Belgium centration-time curve (AUC) and maximum plasma drug concentration $\left(C_{\max }\right)$, as well as half-life and other pharmacokinetic parameters. Also, it is not influenced in a relevant manner by age, sex, ethnicity, advanced renal insufficiency, or moderate hepatic impairment. No clinically relevant drug-drug interactions were observed following co-administration of rotigotine with levodopa/carbidopa, domperidone, or the CYP450 inhibitors cimetidine or omeprazole. Also, pharmacodynamics and pharmacokinetics of an oral hormonal contraceptive were not influenced by rotigotine co-administration. Rotigotine was generally well tolerated, with an adverse event profile consistent with dopaminergic stimulation and use of a transdermal patch. These observations, combined with the long-term efficacy demonstrated in clinical studies, support the use of rotigotine as a continuous non-ergot $\mathrm{D}_{3} / \mathrm{D}_{2} / \mathrm{D}_{1}$ dopamine receptor agonist in the treatment of PD and RLS.

\section{Key Points}

Rotigotine transdermal system shows doseproportional pharmacokinetics and provides stable plasma concentrations over the 24-h application time period.

No relevant drug-drug interactions could be shown with typical concomitant medications or drugs with potential influence on the metabolism of rotigotine.

No influence of intrinsic factors like hepatic or renal impairment, age, or gender could be shown.

The behavior of rotigotine in the body is unaffected by Parkinson's disease and restless legs syndrome disease states. 


\section{Introduction}

Parkinson's disease (PD) and restless legs syndrome (RLS) are two common yet distinct neurological disorders for which dopaminergic therapy has proven valuable. PD is a progressive neurodegenerative disorder that afflicts approximately $1.6 \%$ of adults over 65 years of age, with a higher rate in men $[1,2]$. The underlying pathophysiology of PD is the selective loss of dopaminergic neurons in the substantia nigra [3]. New discoveries over the past decade have led to increased therapeutic options [3, 4]. Patients with PD have a characteristic set of signs and symptoms, primarily movement-related motor symptoms (e.g., tremor at rest, muscle rigidity, bradykinesia, and postural instability) and non-motor symptoms (e.g., sleep disturbance, cognitive dysfunction or dementia, mood, and gastrointestinal/bladder disturbances) [5]. Motor symptoms are initially asymmetric, but often become bilateral with advanced disease [5-7]. Up to $90 \%$ of patients with PD develop speech impairments during the course of their disease [8]. Depression, anxiety, dementia, psychosis, and sleep disturbances often accompany PD [5-7]. In some patients, neuropsychiatric problems and sleep disturbance may have a greater impact on quality of life than the motor symptoms of PD [9-11].

Whilst levodopa is the standard of care in advanced PD, its benefits are short-lived, requiring frequent dose escalation and chronic administration that eventually leads to an increased rate and severity of dyskinesia and 'off' periods [12]. Another approach to the management of PD is the use of orally administered dopamine receptor agonists, such as pramipexole and ropinirole, as monotherapy early in the disease course, and concomitantly with levodopa in advanced stages $[6,13]$. Initial therapy with a dopamine agonist rather than levodopa may reduce the risk of motor complications [13]. However, intermittent oral treatment with levodopa or dopamine agonists results in pulsatile stimulation of striatal dopamine receptors which does not reflect the continuous stimulation observed under physiological conditions $[13,14]$. The problems associated with fluctuating striatal dopaminergic activity due to peroral treatment led to the concept of continuous dopaminergic stimulation in the brain as an alternative treatment approach.

RLS is a motor disorder characterized by the urge to move the legs during periods of evening rest or inactivity and is accompanied by unpleasant sensations (paresthesia, itching, pain) [15]. It affects up to $11 \%$ of the general population, with a two-fold preponderance among women [16]. The syndrome has a hereditary component as there is a 6.7-fold increased risk in patients whose first-degree relatives have early-onset disease (i.e., occurrence before
45 years of age) [17]. Abnormalities in the central, subcortical dopamine pathways and impaired iron homeostasis may also cause RLS [18]. Initially, symptoms occur predominantly during the evening and night. Over time, patients with advanced disease often develop debilitating symptoms during the day. Dopaminergic agents in low doses are the recommended first-line pharmacological therapy for moderate to severe RLS [19]. A main complication of dopaminergic RLS therapy can be the development of augmentation, characterized by an overall worsening of symptoms beyond pre-treatment levels [20]. Augmentation has been reported in 36 of 60 patients receiving levodopa in a 6-month, open-label, multicenter study [21], but appears to occur less frequently with longeracting dopamine agonists [22].

Rotigotine, (6S)-6-(propyl[2-(2-thienyl)ethyl]amino)5,6,7,8-tetrahydro-1-naphthalenol, is a dopamine receptor agonist approved for the daily treatment of early- and advanced-stage idiopathic PD and moderate to severe RLS in Europe, the USA, and other countries. Table 1 gives the available dose strengths and their related drug content and patch size. Continuous transdermal delivery of rotigotine maintains stable plasma concentrations of unconjugated active parent drug over $24 \mathrm{~h}$ with a single daily application [23]. Transdermal application has several key advantages over conventional oral systemic therapy, including elimination of variables influencing gut absorption (e.g., impaired gastrointestinal motility, food effects); direct entry into the systemic circulation, avoiding 'first pass' effects of the liver; and utility in perioperative and intensive care settings.

The purpose of this narrative review is to provide a comprehensive account of available data describing the single-dose and steady-state pharmacokinetics of rotigotine following administration via a transdermal patch in healthy subjects and in patients with PD and RLS. Managing the use of the rotigotine transdermal system in special patient populations and those receiving concomitant drugs is also discussed.

\section{Mechanism of Action}

The parent drug rotigotine, in its unconjugated state, is the pharmacologically active compound at the dopamine receptor. Whilst the exact mechanism of action of rotigotine as a treatment for PD is not completely understood, rotigotine has in vitro activity that spans the dopamine $\mathrm{D}_{1}$ through $\mathrm{D}_{5}$ receptors, as well as select adrenergic and serotonergic sites [24]. Based on the distribution of the different dopamine receptors in the brain and their contribution to motor coordination, rotigotine is best described as a $D_{3} / D_{2} / D_{1}$ receptor agonist. Recent studies using recombinant dopamine $\mathrm{D}_{1}, \mathrm{D}_{2}$, 
Table 1 Rotigotine transdermal patches

\begin{tabular}{lll}
\hline Patch surface area $\left(\mathrm{cm}^{2}\right)$ & Total drug content in patch $(\mathrm{mg})$ & Nominal dose delivered in $24 \mathrm{~h}(\mathrm{mg})$ \\
\hline 5 & 2.25 & $1^{\mathrm{a}}$ \\
10 & 4.5 & $2^{\mathrm{a}, \mathrm{b}}$ \\
15 & 6.75 & $3^{\mathrm{a}}$ \\
20 & 9 & $4^{\mathrm{b}}$ \\
30 & 13.5 & $6^{\mathrm{b}}$ \\
40 & 18 & $8^{\mathrm{b}}$ \\
\hline
\end{tabular}

Doses $>8 \mathrm{mg} / 24 \mathrm{~h}$ may be achieved by application of a combination of several patches

a Approved for treatment of restless legs syndrome

b Approved for treatment of Parkinson's disease and $\mathrm{D}_{3}$ receptors and $\left[{ }^{3} \mathrm{H}\right]$ rotigotine instead of $\left[{ }^{3} \mathrm{H}\right]$ antagonists as radioligands in binding and functional assessments confirmed the high affinity binding of rotigotine on $\mathrm{D}_{3}$ and $\mathrm{D}_{2}$ receptors, but also showed a similarly high affinity towards the $D_{1}$ receptor [24]. Thus, in contrast to other dopamine receptor agonists, which predominantly act as $\mathrm{D}_{2}$ and $\mathrm{D}_{3}$ receptor agonists, rotigotine also acts on $\mathrm{D}_{1}$ dopamine receptors, suggesting that rotigotine more closely resembles dopamine or apomorphine than other dopamine agonists [25]. However, rotigotine is also an antagonist at $\alpha_{2 \mathrm{~B}}$ adrenergic receptors and an agonist at $5-\mathrm{HT}_{1 \mathrm{~A}}$ receptors, and interaction could contribute to its beneficial efficacy in vivo [24]. Rotigotine was shown not to interact with $5-\mathrm{HT}_{2 \mathrm{~B}}$ receptors [24]. Overall, the capacity of rotigotine to stimulate dopamine $\mathrm{D}_{1}-\mathrm{D}_{3}$ receptors within the caudate putamen regions of the brain is likely the basis for its efficacy in patients with PD [24].

Several animal models have characterized the pre- and post-synaptic activity of rotigotine. The pre-synaptic activity of rotigotine is exemplified by hypomotility following low doses of the agonist [26], as well as reduction in $\gamma$ butyrolactone-stimulated dopamine synthesis [27] and extracellular dopamine concentrations [28]. Post-synaptic activity of rotigotine was demonstrated in rats via two models: reserpine reversal and stereotypy induction [27]. In addition, observations of contraversive turning and enhanced locomotor activity in 6-hydroxydopamine-treated rat and MPTP-treated monkey models further prove its post-synaptic activity on dopamine receptors $[29,30]$.

\section{Pharmacokinetic Properties}

\subsection{Bioavailability and Metabolism}

The physicochemical properties of rotigotine are compatible with drug permeation through the skin, which not only avoids the extensive 'first pass' effect after oral administration but also facilitates continuous drug administration and systemic exposure over $24 \mathrm{~h}$. In a pilot study, a 24-h patch-on period of one transdermal rotigotine patch $\left(4 \mathrm{mg} ; 20 \mathrm{~cm}^{2}\right)$ resulted in a steady rise in plasma drug concentrations after a 2- to 4-h lag phase (data on file, UCB Pharma). The mean maximum plasma drug concentration $\left(C_{\max } ; 0.56 \mathrm{ng} / \mathrm{mL}\right)$ was evident $19 \mathrm{~h}$ postapplication [time to reach $C_{\max }\left(t_{\max }\right)$ ] before plasma drug concentrations declined to $0.02 \mathrm{ng} / \mathrm{mL} 24 \mathrm{~h}$ after patch removal. The mean area under the plasma concentrationtime curve (AUC) from zero up to the last quantifiable plasma concentration $\left(\mathrm{AUC}_{0_{-\mathrm{t}}}\right)$ was $11.1 \mathrm{ng} \cdot \mathrm{h} / \mathrm{mL}$, and the mean terminal elimination half-life $\left(t_{1 / 2}\right)$ was $5.3 \mathrm{~h}$ (data on file, UCB Pharma). Systemic exposure to rotigotine approximately doubled when two patches were applied simultaneously, without any material change in the lag phase, $t_{\max }$, and $t_{1 / 2}$ (data on file, UCB Pharma). Analysis of plasma samples after transdermal application of $8 \mathrm{mg} /$ $24 \mathrm{~h}$ rotigotine detected presence of a despropyl metabolite in some samples close to the lower limit of quantification.

The absolute bioavailability and metabolism of the patch was determined in a randomized, two-sequence, twoperiod, crossover study in six male subjects who were administered the transdermal rotigotine patch $(2 \mathrm{mg}$ unlabelled/24 h) and an intravenous continuous 12-h rotigotine infusion $\left(1.2 \mathrm{mg}\right.$ of rotigotine including $0.6 \mathrm{mg}$ of $\left[{ }^{14} \mathrm{C}\right.$ rotigotine]) [31]. Profiles of unconjugated rotigotine concentrations versus time in plasma were similar following administration of both formulations (Fig. 1). Furthermore, similar levels of rotigotine $C_{\max }$ and a similar decreasing profile of these concentrations after patch removal was observed. Median absolute bioavailability of transdermal rotigotine was $37 \%$ of the applied dose after the 24-h application time period ( $>60 \%$ of the drug delivered to the skin) [31]. Systemically absorbed rotigotine is rapidly metabolized following intravenous administration (Fig. 2). Conjugation of the parent compound results in two primary metabolites: rotigotine sulfate and rotigotine glucuronide. In addition, the drug undergoes oxidative 


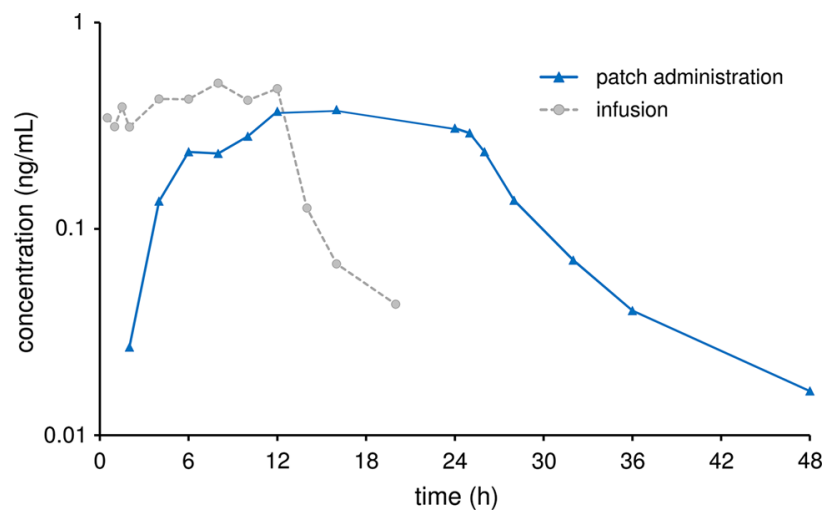

Fig. 1 Mean rotigotine plasma concentrations after application of rotigotine transdermal patch $(2 \mathrm{mg} / 24 \mathrm{~h})$ or intravenous infusion of $1.2 \mathrm{mg}$ over $12 \mathrm{~h}$. Adapted with permission from Cawello et al. [31]

biotransformation and is converted to two $N$-desalkylated metabolites ( $N$-desthienylethyl- and $N$-despropyl-rotigotine), each of which have short-lived activity as they are rapidly conjugated to inactive moieties. Elimination of rotigotine metabolites was primarily via urine $(71 \%)$ and to a minor extent into feces $(23 \%)$. Renal elimination of the unchanged parent compound was negligible $(<1 \%)$ [31].

\subsection{Mass Balance}

The single-dose disposition of transdermally applied rotigotine in male subjects was characterized in a phase I study of six Caucasian men who received a single transdermal patch containing radiolabeled rotigotine $(2 \mathrm{mg} /$ $24 \mathrm{~h}$ ) applied to the forearm for $24 \mathrm{~h}$ [32]. Measurement of unconjugated rotigotine in plasma, urine, and fecal samples was determined by liquid chromatography with tandem mass spectrometry. Approximately $95 \%$ of administered rotigotine was recovered within $96 \mathrm{~h}$ of transdermal application, including drug left in the patch. Within $24 \mathrm{~h}$, $51 \%$ of the total radioactivity was delivered to the body (46\% of the total radioactivity was absorbed into the systemic circulation and $5 \%$ remained in the skin) to give an apparent total dose (i.e., the dose delivered to the skin of

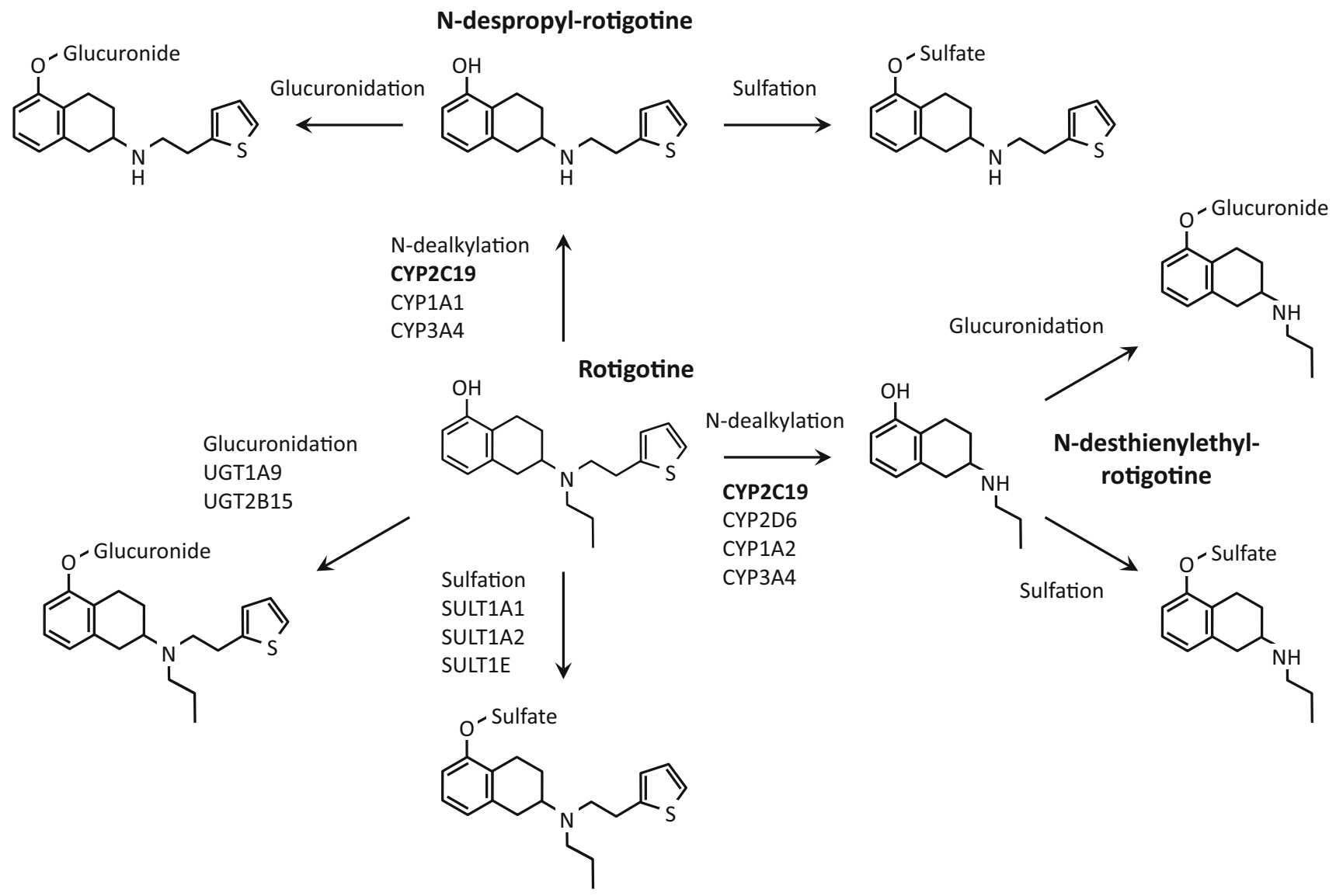

Fig. 2 Metabolic pathway of rotigotine. Adapted with permission from Cawello et al. [31] 
the patient) of $2.3 \mathrm{mg} / 24 \mathrm{~h}$ and an absorbed dose of $2.1 \mathrm{mg} / 24 \mathrm{~h}$. No radiolabel could be detected in plasma since all samples were below the limit of quantitation. Rather, most of the absorbed dose was eliminated in urine (66\%) and to a lesser extent in feces (22\%) within $96 \mathrm{~h}$ of patch application [32]. Mean peak plasma unconjugated rotigotine concentrations of $0.28 \mathrm{ng} / \mathrm{mL}$ were achieved at $24 \mathrm{~h}$ post-application.

\subsection{Dose Proportionality}

Based on pooled data from 17 phase I studies in largely healthy subjects, transdermally administered rotigotine exhibited a dose-proportional pharmacokinetic profile across the entire therapeutic dose range for RLS and the lower half of the therapeutic dose range for PD (data on file, UCB Pharma; Fig. 3). This pooled analysis included data from a total of 522 subjects (338 healthy subjects, 23 patients with idiopathic RLS, 63 patients with early-stage PD, 66 patients with advanced PD, eight subjects with moderate hepatic impairment, and 24 subjects with renal impairment) who received administration of rotigotine 1-24 mg/24 h.

Three studies provide evidence that transdermal administration of rotigotine provides dose-proportional pharmacokinetics in patients with early- and advancedstage idiopathic PD [23, 33, 34]. Two of these (SP630 and SP864) were included in the aforementioned pooled analysis. In SP630, 63 patients with early PD received an initial daily rotigotine dose of $2 \mathrm{mg} / 24 \mathrm{~h}$, which was increased during a 24-day titration phase in 6-day increments of $2 \mathrm{mg} / 24 \mathrm{~h}$ to a maintenance dose of $8 \mathrm{mg} / 24 \mathrm{~h} \mathrm{[23].}$ Patients received the final dose for an additional 6 days to

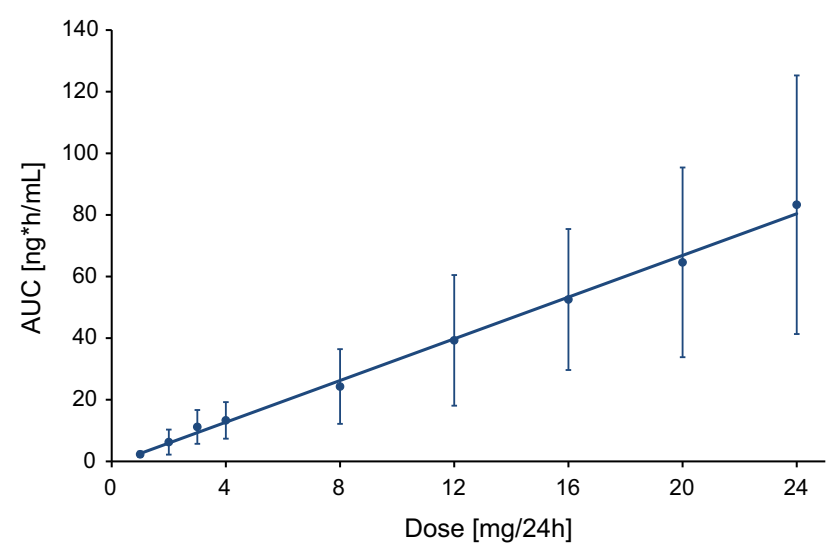

Fig. 3 Dose proportionality of rotigotine pharmacokinetics based on mean $( \pm \mathrm{SD})$ area under the plasma drug concentration-time curve (AUC) from $1 \mathrm{mg} / 24 \mathrm{~h}$ to supratherapeutic dose rates of $24 \mathrm{mg} / 24 \mathrm{~h}$. Data derived from 17 phase I studies comprising healthy subjects and patients with restless legs syndrome and early- and advanced-stage Parkinson's disease ensure steady-state conditions. A dose-proportional increase in steady-state trough plasma concentrations of unconjugated rotigotine was observed over the therapeutic dose range of $2 \mathrm{mg} / 24 \mathrm{~h}$ to $8 \mathrm{mg} / 24 \mathrm{~h}$ rotigotine. Mean $C_{\text {trough,ss }}$ values increased from $0.17 \mathrm{ng} / \mathrm{mL}$ to $0.90 \mathrm{ng} / \mathrm{mL}$ unconjugated rotigotine [23]. The SP864 study demonstrated dose-proportional pharmacokinetics of rotigotine at steady state in patients with advanced PD $(n=66)$ from $8 \mathrm{mg} / 24 \mathrm{~h}$ rotigotine to the maximum therapeutic dose of $16 \mathrm{mg} / 24 \mathrm{~h}$, and supratherapeutic doses of 20 and $24 \mathrm{mg} /$ $24 \mathrm{~h}$ [33]. Patients in this study received titrated daily doses of $4,8,12,16,20$, and $24 \mathrm{mg} / 24 \mathrm{~h}$ during study weeks $1,2,3,4,5$, and 6 , respectively. Mean $C_{\max }$ at steady state $\left(C_{\text {max,ss }}\right)$ values increased from $1.38 \mathrm{ng} / \mathrm{mL}$ with $8 \mathrm{mg} / 24 \mathrm{~h}$ rotigotine to $4.34 \mathrm{ng} / \mathrm{mL}$ with $24 \mathrm{mg} / 24 \mathrm{~h}$ rotigotine [33]. Finally, SP591 was a dose-escalation study in 34 patients (mean age 69 years) with advanced PD. Patients were initiated with a starting dose of rotigotine transdermal system of $4 \mathrm{mg} / 24 \mathrm{~h}$ and titrated over 42-77 days to a target dose of $24 \mathrm{mg} / 24 \mathrm{~h}$ [34]. Plasma rotigotine concentrations were measured in a subset of patients immediately prior to patch removal and 2-12 h following application. Mean unconjugated rotigotine plasma concentrations were found to increase proportionally with dose: $0.5 \mathrm{ng} / \mathrm{mL}$ for $4 \mathrm{mg} / 24 \mathrm{~h}(n=3), 1.2 \mathrm{ng} / \mathrm{mL}$ for $8 \mathrm{mg} / 24 \mathrm{~h}(n=3), 2.4 \mathrm{ng} / \mathrm{mL}$ for $12 \mathrm{mg} / 24 \mathrm{~h}(n=3)$, $3.4 \mathrm{ng} / \mathrm{mL}$ for $16 \mathrm{mg} / 24 \mathrm{~h}(n=3), 3.8 \mathrm{ng} / \mathrm{mL}$ for $20 \mathrm{mg} /$ $24 \mathrm{~h}(n=6)$, and $6.0 \mathrm{ng} / \mathrm{mL}$ for $24 \mathrm{mg} / 24 \mathrm{~h}(n=3)$. Variability between subjects was high [34].

\subsection{Steady-State Pharmacokinetics}

In the 14-day SP503 study, in which multiple daily doses of rotigotine transdermal patch $\left(4.5 \mathrm{mg} ; 10 \mathrm{~cm}^{2}\right)$ were administered to 30 healthy men, steady-state plasma concentrations were achieved within 1-2 days of dosing (data on file, UCB Pharma). Changes in plasma drug concentrations suggestive of accumulation were not observed. Instead, mean plasma profiles showed relatively stable rotigotine concentrations after multiple dosages (Fig. 4), and mean trough plasma concentration remained stable over the treatment period.

The stability of mean 24-h plasma rotigotine concentrations at steady-state was quantified in 40 evaluable, healthy Caucasian male subjects (mean age of 24 years) who applied doses $(3 \mathrm{mg} / 24 \mathrm{~h})$ of the transdermal system either as a single large patch or two smaller patches applied to six different body sites [23]. A randomized, crossover design was used for this purpose, wherein subjects received an initial dosage of $2 \mathrm{mg} / 24 \mathrm{~h}$ rotigotine for 3 days followed by $3 \mathrm{mg} / 24 \mathrm{~h}$ rotigotine, either in a $15-\mathrm{cm}^{2}$ patch or in a patch combination of $1 \times 5 \mathrm{~cm}^{2}(1 \mathrm{mg} / 24 \mathrm{~h})$ plus $1 \times 10 \mathrm{~cm}^{2}(2 \mathrm{mg} / 24 \mathrm{~h})$, until day 13 , when they switched 


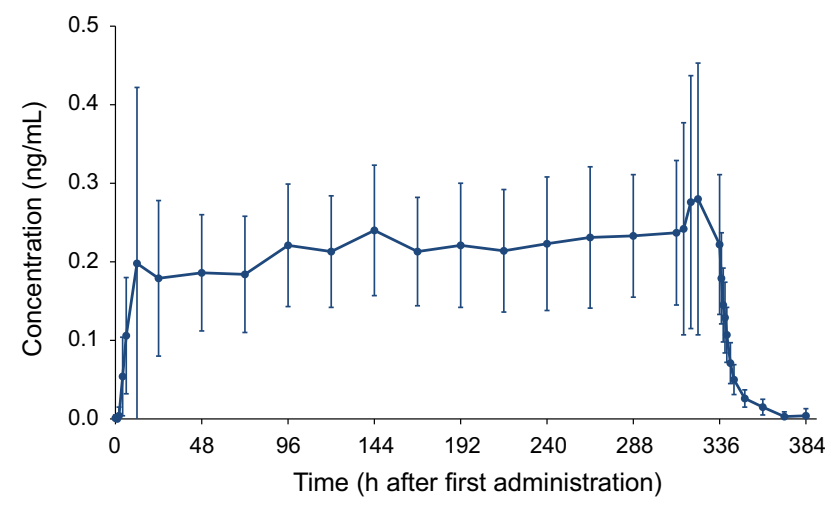

Fig. 4 Plasma rotigotine concentrations (arithmetic mean \pm SD) in 30 healthy men during a 14-day multiple dosage regimen of rotigotine transdermal patch $\left(2 \mathrm{mg} / 24 \mathrm{~h} ; 10 \mathrm{~cm}^{2}\right)$

to the alternative regimen for day 13 and day 14 dosing. Subjects were also randomized to a daily patch rotation schedule for six application sites (i.e., abdomen, thigh, hip, flank, shoulder, or upper arm), except for days $12-14$, when each participant used one specific body site for patch application [23].

Stable steady-state 24-h plasma concentrations for unconjugated rotigotine were observed across all six application sites [23]. Mean rotigotine plasma concentrations decreased slightly after application of a new patch owing to a lag phase of approximately $2 \mathrm{~h}$ followed by an increase to plateau concentrations. $C_{\mathrm{max}, \mathrm{ss}}$ was reached after a median of $16 \mathrm{~h}$ (range $0-20 \mathrm{~h}$ ) after patch application. Immediately prior to patch removal, mean rotigotine plasma concentrations were equal to the corresponding concentrations at time of patch removal on the previous days. Delivery via a single large patch compared with a combination of smaller patches did not influence the bioavailability of rotigotine, as evidenced by point estimates for the ratios of geometric means between the treatments for $C_{\max , s s}[0.52$ vs. $0.54 \mathrm{ng} / \mathrm{mL}$; ratio $0.97,90 \%$ confidence interval (CI) 0.92-1.03] and $\mathrm{AUC}_{0-24 \mathrm{~h}, \mathrm{ss}}(9.12$ vs. $9.56 \mathrm{ng} \cdot \mathrm{h} / \mathrm{mL}$; ratio $0.95,90 \% \mathrm{CI}$ 0.91-1.01). Steady-state conditions in healthy subjects were similar to patients with early-stage PD (see below). Bioavailability showed some variability depending on patch application site; the respective mean ratio for $\mathrm{AUC}_{0-24} \mathrm{~h}$,ss normalized for total drug content ranged between 0.87 (90\% CI 0.83-0.93) for abdomen versus flank, and 1.46 (90\% CI 1.38-1.54) for shoulder versus thigh [23].

\subsection{Special Populations}

\subsubsection{Effects of Sex}

Pharmacokinetics of single-dose rotigotine transdermal system $(2 \mathrm{mg} / 24 \mathrm{~h})$ were assessed in 48 healthy male and female subjects of either Caucasian or Japanese ethnicity during and after a patch-on period of $24 \mathrm{~h}$ [35]. Female subjects had higher mean $C_{\max }$ (Caucasians 0.23 vs. $0.17 \mathrm{ng} / \mathrm{mL}$; Japanese 0.29 vs. $0.17 \mathrm{ng} / \mathrm{mL}$ ) and AUC from zero up to infinity $\left(\mathrm{AUC}_{0-\infty}\right)$ (Caucasians 4.74 vs. $3.70 \mathrm{ng} \cdot \mathrm{h} / \mathrm{mL}$; Japanese 5.8 vs. $3.5 \mathrm{ng} \cdot \mathrm{h} / \mathrm{mL}$ ) than male subjects in both ethnic groups [35]. The relative nominal differences in plasma concentrations of unconjugated rotigotine and derived pharmacokinetic parameters between genders were mitigated when corrected for differences in body weight and apparent dose [35].

\subsubsection{Effects of Ethnicity}

Small differences in the pharmacokinetics of unconjugated and total rotigotine as well as high inter-individual variability in drug exposure were observed between healthy Japanese and Caucasian subjects following single-dose and multiple daily doses of the transdermal system [35]. In an open-label, parallel-group study, healthy male and female subjects of Japanese $(n=24)$ or Caucasian $(n=24)$ ethnic origin were matched by sex, body mass index, and age before application of a single transdermal patch delivering $2 \mathrm{mg} / 24 \mathrm{~h}$ rotigotine to the ventral/lateral abdomen for $24 \mathrm{~h}$ [35]. The mean apparent dose of rotigotine was comparable in both groups $(2.0 \pm 0.5 \mathrm{mg}$ for Japanese subjects and $2.1 \pm 0.6 \mathrm{mg}$ for Caucasian subjects) and in line with the labeled drug delivery rate over $24 \mathrm{~h}$. Plasma concentration-time profiles of unconjugated rotigotine were similar for both ethnic groups, as evidenced by geometric mean ratios (without normalization) for $C_{\max }$ of 1.14 (90 \% CI 0.88-1.47) and AUC from time zero to last quantifiable concentration $\left(\mathrm{AUC}_{0-\mathrm{t}}\right)$ of $1.10(90 \% \mathrm{CI}$ 0.84-1.44). For both parameters, the differences between groups were minimized by normalization for body weight and increased by normalization for apparent dose, but normalization for both factors resulted in a ratio for Japanese versus Caucasians of 1.08 (90\% CI 0.88-1.32) for $C_{\max }$ and 1.05 (90\% CI 0.85-1.28) for $\mathrm{AUC}_{0-\mathrm{t}}$. However, a difference between ethnic groups was observed for total rotigotine exposure, with geometric mean ratios for $C_{\max }$ $1.30(90 \% \mathrm{CI} 1.12-1.52)$ and $\mathrm{AUC}_{0-\mathrm{t}} 1.25(90 \% \mathrm{CI}$ $1.08-1.45)$ exceeding unity even after correction for body weight and apparent dose [35].

Multiple doses of open-label rotigotine transdermal system $(1,2$, and $4 \mathrm{mg} / 24 \mathrm{~h})$ in 12 Japanese and 12 Caucasian men and women produced mean plasma concentration-time profiles for unconjugated rotigotine that were similar in both ethnic groups at day 3 for each dosage [36]. When the data were pooled across dose rates without normalization, statistical comparison (Japanese vs. Caucasian) for $C_{\max , s s}(1.06,90 \%$ CI $0.84-1.34)$ and $\mathrm{AUC}_{0-24 \mathrm{~h}, \mathrm{ss}}(1.09,90 \% \mathrm{CI}$ 0.86-1.37) for unconjugated rotigotine indicated no relevant differences between the 
two ethnic groups. Normalization for weight and apparent dose reduced variability as indicated by narrower $90 \%$ CIs for $C_{\text {max,ss }}(1.11,90 \%$ CI $0.92-1.33)$ and $\mathrm{AUC}_{0-24, \mathrm{ss}}(1.13$, $90 \%$ CI 0.94-1.36). Plasma level of total rotigotine was about ten times higher than the plasma level of unconjugated rotigotine. Unlike in the single-dose study [36], Caucasian subjects had a slightly higher concentration of total rotigotine than Japanese subjects, based on the weight- and apparent dose-normalized point estimate of geometric mean ratios for $C_{\text {max,ss }}(0.90,90 \%$ CI $0.79-1.03)$ and $\mathrm{AUC}_{0-24 \mathrm{~h}, \mathrm{ss}}(0.89,90 \%$ CI $0.79-1.00)$. Overall, the findings from these two studies suggest similar dose requirements for Japanese and Caucasian populations [36].

Pharmacokinetic data collected in 48 healthy Korean men and women found that approximately $50 \%$ of the total drug content of the rotigotine patch was delivered to the skin over $24 \mathrm{~h}$ [37], which is a similar percentage to that observed in the mass balance study of Caucasian men [32]. At the $2 \mathrm{mg} / 24 \mathrm{~h}$ and $4 \mathrm{mg} / 24 \mathrm{~h}$ dose rate, respectively, steady-state geometric means for unconjugated rotigotine $C_{\max }$ were 0.35 and $0.84 \mathrm{ng} / \mathrm{mL}$ and for $\mathrm{AUC}_{0-24 \mathrm{~h}}$ were 5.88 and $13.74 \mathrm{ng} \cdot \mathrm{h} / \mathrm{mL}$ [37]. Thus, the pharmacokinetic parameters of unconjugated rotigotine in Korean subjects were similar to that observed in separate studies of Caucasian and Japanese subjects [35].

The pharmacokinetics of a single-dose, 24-h abdominal application of transdermal rotigotine $2 \mathrm{mg} / 24 \mathrm{~h}$ was assessed in a single-center, open-label study of healthy black African $(n=21)$ and Caucasian subjects $(n=24)$ (data on file, UCB Pharma). Based on visual inspection, Fig. 5 shows that there was little difference between the two ethnic groups regarding the plasma concentration profile of unconjugated rotigotine. Again, a lag phase of $2 \mathrm{~h}$ was observed before the detection of unconjugated

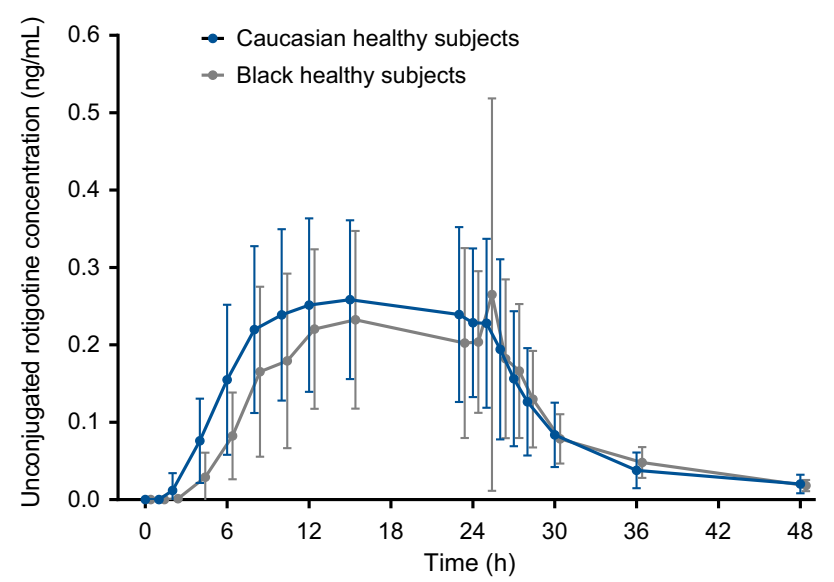

Fig. 5 Plasma rotigotine concentrations (arithmetic mean \pm SD) in 21 black African and 24 Caucasian subjects after single-dose administration of rotigotine transdermal system $2 \mathrm{mg} / 24 \mathrm{~h}$ rotigotine in plasma. Despite the Caucasian and black African subjects being well matched demographically and both cohorts receiving the same nominal dose, mean plasma rotigotine concentrations at most time points in the Caucasian group were slightly higher than in the black African group. Pharmacokinetic analysis of AUC ratios revealed that total systemic exposure to rotigotine in black African subjects may be slightly lower than in Caucasian subjects (Table 2).

\subsubsection{Effects of Liver and Renal Impairment}

Steady-state pharmacokinetics following administration of a single rotigotine transdermal patch with a 24 -h patch-on period ( $2 \mathrm{mg} / 24 \mathrm{~h}$ over 3 days) were evaluable in eight patients with moderate hepatic impairment (Child-Pugh grade B) versus eight healthy adult male subjects [38]. Mean plasma concentration-time curves for unconjugated rotigotine showed no considerable differences between healthy subjects and subjects with moderate hepatic impairment. For unconjugated rotigotine, point estimates for $C_{\text {max,ss }}$ and $\mathrm{AUC}_{0-24} \mathrm{~h}, \mathrm{ss}$ between the two groups (geometric mean ratio of impaired hepatic function to normal) were 0.94 (90\% CI 0.66-1.35) and 0.90 (90\% CI 0.59-1.38), respectively. Compared with healthy subjects, subjects with moderate hepatic impairment had a slightly shorter mean unconjugated rotigotine elimination half-life $(6.7$ vs. $5.6 \mathrm{~h})$, similar mean renal clearance $(0.11$ vs. $0.10 \mathrm{~L} / \mathrm{h}$ ), and higher overall total body clearance (both 332 vs. $377 \mathrm{~L} / \mathrm{h}$ ). The generally high value for total body clearance can be mainly attributed to the rapid and complete metabolism, as described above [31]. Overall, a moderate degree of liver insufficiency did not alter the steady-state pharmacokinetics of unconjugated rotigotine to a relevant extent. The lack of accumulation of unconjugated rotigotine in patients with moderate liver dysfunction provides evidence that dose adjustment is not required for patients with mild or moderate hepatic insufficiency.

Assessment of the pharmacokinetics of unconjugated rotigotine following a single transdermal $(2 \mathrm{mg} / 24 \mathrm{~h}) 24-\mathrm{h}$ patch-on period was explored in 32 subjects with varying degrees of renal function [39]. Pharmacokinetic data were available for eight healthy subjects, one subject with mild impairment of renal function, seven patients with moderate impairment of renal function, eight patients with severe impairment of renal function, and eight patients with endstage renal disease (ESRD) requiring hemodialysis. Median plasma concentration-time profiles were similar for all renal function cohorts, with peak concentrations occurring approximately $16 \mathrm{~h}$ following patch application, with the exception of the ESRD-hemodialysis cohort, who achieved maximum blood levels $24 \mathrm{~h}$ post-application. As expected, 
Table 2 Race-based rotigotine pharmacokinetic metrics in 21 black African and 24 Caucasian subjects who received single-dose administration of rotigotine transdermal system $2 \mathrm{mg} / 24 \mathrm{~h}$

\begin{tabular}{lllll}
\hline Parameter $($ mean $\pm \mathrm{SD})$ & Black African $(n=21)$ & Caucasian $(n=24)$ & Geometric mean ratio $^{\mathrm{a}}$ & $90 \%$ CI \\
\hline $\mathrm{AUC}_{0-24} \mathrm{~h}(\mathrm{ng} \cdot \mathrm{h} / \mathrm{mL})$ & $3.72 \pm 1.81$ & $4.63 \pm 1.78$ & 0.73 & $0.56-0.96$ \\
$\mathrm{AUC}_{0-t}(\mathrm{ng} \cdot \mathrm{h} / \mathrm{mL})$ & $5.39 \pm 2.53$ & $6.19 \pm 2.49$ & 0.81 & $0.64-1.06$ \\
$\mathrm{AUC}_{0-\infty}(\mathrm{ng} \cdot \mathrm{h} / \mathrm{mL})$ & $5.64 \pm 2.57$ & $6.41 \pm 2.66$ & 0.83 & $0.66-1.08$ \\
$C_{\max }(\mathrm{ng} / \mathrm{mL})$ & $0.33 \pm 0.24$ & $0.34 \pm 0.13$ & 0.87 & $0.69-1.12$ \\
$t_{\max }(\mathrm{h})$ & $18 \pm 6$ & $17 \pm 7$ & - & - \\
$t_{1 / 2}(\mathrm{~h})$ & $7.4 \pm 2.6$ & $6.5 \pm 3.6$ & - & - \\
\hline
\end{tabular}

$A U C_{0-24}{ }_{h}$ area under the plasma concentration versus time curve from zero up to $24 \mathrm{~h}, A U C_{0-t}$ area under the plasma concentration-time curve from zero up to the last analytically quantifiable concentration, $A U C_{0-\infty}$ area under the plasma concentration-time curve from zero up to infinity, $C I$ confidence interval, $C_{\max }$ maximum plasma concentration, $t_{1 / 2}$ terminal half-life, $t_{\max }$ time to reach a maximum plasma concentration

${ }^{\text {a }}$ Black African/Caucasian

conjugated rotigotine concentrations increased with worsening renal function [39], as the inactive conjugates are mainly eliminated by renal excretion [31]. Bioavailability of unconjugated rotigotine was not affected by varying renal function, as the respective ratios for $C_{\max }$ and $\mathrm{AUC}_{0-t}$ between the groups with moderate to severe renal impairment and healthy subjects were 0.93 (90\% CI 0.60-1.47) and 0.88 (90\% CI 0.58-1.33) for moderate renal impairment, 1.18 (90\% CI $0.76-1.82)$ and 1.14 (90\% CI 0.76-1.71) for severe renal impairment, and 1.25 (90\% CI 0.81-1.93) and 1.05 (90\% CI 0.70-1.57) for end-stage renal insufficiency requiring hemodialysis [39]. The elimination half-life of rotigotine was also comparable among the cohorts. With point estimates near 1, these data suggest that no dose adjustments are required for rotigotine transdermal system in patients with different stages of chronic renal insufficiency, including patients on hemodialysis. These observations are particularly valuable as RLS is often a co-morbid condition in patients with ESRD.

\subsection{Target Population: Early- to Advanced-Stage PD and Moderate to Severe RLS}

\subsubsection{Steady-State Pharmacokinetics}

Two phase I studies (SP630, SP651) in overall 99 subjects with early-stage PD assessed rotigotine steady-state pharmacokinetics following administration of the once-daily patch at the highest therapeutic dose for treatment of early PD $(8 \mathrm{mg} / 24 \mathrm{~h})$ [23]. Rotigotine release from the patch, which is an indicator for the dose absorbed [31], ranged from $31-48 \%$. Similar to healthy subjects (see above), stable steady-state 24-h plasma concentrations of unconjugated rotigotine were observed in both studies [23]. For study SP630, a mean $C_{\text {max,ss }}$ of $1.35 \mathrm{ng} / \mathrm{mL}$ was reached at a median of $16 \mathrm{~h}$ and mean $\mathrm{AUC}_{0-24 \mathrm{~h}, \mathrm{ss}}$ was $19.62 \mathrm{ng} \cdot \mathrm{h} /$ $\mathrm{mL}$. Corresponding mean values for study SP651 were 1.13 $\mathrm{ng} / \mathrm{mL}$ and $17.75 \mathrm{ng} \cdot \mathrm{h} / \mathrm{mL}$. In 66 patients with advanced
PD who received $8-24 \mathrm{mg} / 24 \mathrm{~h}$ rotigotine via the transdermal system over a 6-week period, stable steady-state plasma concentrations of unconjugated rotigotine were demonstrated over the 24-h application time period at each dose rate [33]. Over the 24-h sample period, mean steadystate plasma concentrations of unconjugated rotigotine fluctuated close to $1 \mathrm{ng} / \mathrm{mL}$ at the $8 \mathrm{mg} / 24 \mathrm{~h}$ dose rate, increasing by $0.5 \mathrm{ng} / \mathrm{mL}$ for every $4 \mathrm{mg} / 24 \mathrm{~h}$ dose increase up to a slightly broader range around $3.5 \mathrm{ng} / \mathrm{mL}$ for the $24 \mathrm{mg} / 24 \mathrm{~h}$ dose [33].

Rotigotine elimination after patch removal was assessed in 20 subjects with RLS at steady-state conditions for $4 \mathrm{mg} / 24 \mathrm{~h}$, using one- and two-compartment model analyses [40]. The one-compartment model yielded an average elimination half-life of 5-7 h. Use of a twocompartment model revealed initial rapid systemic clearance of the drug (e.g., from 0.65 to $0.15 \mathrm{ng} / \mathrm{mL}$ within 4-6 $\mathrm{h}$ post-removal) with an elimination half-life (alpha phase) of $2-3 \mathrm{~h}$. The subsequent terminal elimination half-life (beta phase) was approximately $10-20 \mathrm{~h}$, with detection of much lower plasma levels $(0.01-0.03 \mathrm{ng} / \mathrm{mL}$ at $36 \mathrm{~h}$ post-removal).

\subsubsection{Effects of Age and Sex}

A phase I study (SP630) evaluated the effects of age and sex on steady-state rotigotine pharmacokinetics in 63 patients with early idiopathic PD [23]. Rotigotine was initiated at a daily dose of $2 \mathrm{mg} / 24 \mathrm{~h}$ that was increased to a maintenance dose of $8 \mathrm{mg} / 24 \mathrm{~h}$. No major differences were observed between age cohorts and sex in unconjugated rotigotine plasma concentrations or derived pharmacokinetics. Steady-state geometric mean ratios for $\mathrm{AUC}_{0-24 \mathrm{~h}, \mathrm{ss}}$ and $C_{\max }$ (normalized by body weight and apparent dose) comparing patients $<65$ years with those $\geq 65$ years were 1.06 (90\% CI 0.93-1.20) and 1.09 (90\% CI 0.95-1.25), and, for comparison of males to females, were 1.04 (90\% CI 0.92-1.18) and 0.99 (90\% CI 0.86-1.14) [23]. 
In a phase III, multinational, randomized controlled trial (CLEOPATRA-PD) [41], the pharmacokinetic profile of rotigotine following removal and reapplication of transdermal patches was examined in 56 patients with advanced-stage PD [42]. A total of 986 samples with measurable unconjugated rotigotine concentrations were collected immediately before patch removal and 1-4 h after administration of a new patch. Dose proportionality was observed from 2 to $16 \mathrm{mg} / 24 \mathrm{~h}$ during the 7 -week titration phase. At the end of the titration phase and completion of the daily $16 \mathrm{mg} / 24 \mathrm{~h}$ dose, mean plasma drug concentration was $1.2 \mathrm{ng} / \mathrm{mL}$. Maintenance concentrations just prior to patch removal were stable, as indicated by levels of $1.5,1.4$, and $1.3 \mathrm{ng} / \mathrm{mL}$ for days 1 , 29 , and 85 , respectively. As identified in the study assessing rotigotine steady-state pharmacokinetics in patients with early idiopathic PD [23], age $(<65$ or $\geq 65$ years) and sex had no impact on mean trough plasma concentrations of unconjugated rotigotine following removal and reapplication of the transdermal system. Overall, stable plasma levels over the 4-month maintenance phase were observed, with minimal fluctuations following patch change.

\subsubsection{Long-Term Plasma Concentrations of Rotigotine}

In an open-label extension of a phase IIb trial (SP710), rotigotine plasma levels were monitored during long-term treatment with rotigotine transdermal system in 284 patients with moderate to severe idiopathic RLS [43]. Each patient received once-daily transdermal patches of rotigotine titrated within 4 weeks to their optimal dose $(0.5,1.0$, 2.0 , 3.0, or $4.0 \mathrm{mg} / 24 \mathrm{~h}$ ). Valid rotigotine plasma concentrations were available for 187 patients after 1 year and 103 patients after 5 years. Dose proportionality was observed from 0.5 to $4 \mathrm{mg} / 24 \mathrm{~h}$ and confirmed after treatment over 1 and 5 years (Table 3). Comparing the plasma concentration data, stable plasma levels were found across dose rates over the 5-year period, suggesting that long-term administration did not alter the pharmacokinetics of rotigotine.

Table 3 Mean $( \pm \mathrm{SD})$ plasma concentrations of unconjugated rotigotine after year 1 and year 5 of maintenance therapy in 284 patients with moderate to severe idiopathic restless legs syndrome [43].

\section{Drug-Drug Interactions}

\subsection{Drug-Drug Interactions with Common Concomitant Medications}

Four studies have evaluated the drug-drug interaction potential between rotigotine and levodopa/carbidopa, domperidone, oral contraceptives, cimetidine, and omeprazole under steady-state conditions [44-47]. According to the generally accepted regulatory requirements, bioequivalence was concluded (i.e., no relevant interaction) if the $90 \%$ CIs for the ratio of the geometric means for unconjugated rotigotine alone versus in combination with test drugs, or vice versa, were within the $80-125 \%$ acceptance range for all primary pharmacokinetic parameters [48].

\subsubsection{Levodopa/Carbidopa}

In an open-label phase I study, 24 patients with RLS (12 Caucasian men, 12 Caucasian women) received levodopa/carbidopa (100/25 mg twice daily) and rotigotine transdermal system (initial dose $2 \mathrm{mg} / 24 \mathrm{~h}$ for 3 days, followed by $4 \mathrm{mg} / 24 \mathrm{~h}$ ) in a randomized sequence [44]. Treatment sequence A was initiated with rotigotine followed by the combination treatment, while treatment sequence B was initiated with levodopa/carbidopa followed by the combination treatment. Each treatment sequence lasted 12 days. Mean plasma concentration-time profiles of levodopa/carbidopa were similar when given alone or in combination with rotigotine. Likewise, steady-state unconjugated rotigotine plasma concentration-time profiles were not altered in the presence of levodopa/carbidopa (Fig. 6a). Importantly, mean apparent rotigotine doses were similar for both treatment sequences (A: $4.72 \mathrm{mg}$ on day 7 and $4.18 \mathrm{mg}$ on day 10; B: $4.18 \mathrm{mg}$ on day 9 and $4.36 \mathrm{mg}$ on day 12). Derived pharmacokinetic parameters indicated absence of an interaction between levodopa/carbidopa and rotigotine, and vice versa. The geometric means of levodopa/carbidopa $C_{\text {max,ss }}$ and $\mathrm{AUC}_{0-12}$ h.ss with (and without) rotigotine were $1,612 / 160 \mathrm{ng} / \mathrm{mL}(1563 / 152 \mathrm{ng} /$ $\mathrm{mL})$ and $2561 / 789 \mathrm{ng} \cdot \mathrm{h} / \mathrm{mL}(2632 / 764 \mathrm{ng} \cdot \mathrm{h} / \mathrm{mL})$. For

Plasma concentrations at the lower dose rates $(0.5$ and $1 \mathrm{mg} / 24 \mathrm{~h})$ should be interpreted with caution because of the small numbers of patients in those cohorts

\begin{tabular}{lll}
\hline Transdermal rotigotine dosage $(\mathrm{mg} / 24 \mathrm{~h})$ & Plasma drug concentration at year 1 $(\mathrm{ng} / \mathrm{mL})$ & Plasma drug concentration at year 5 $(\mathrm{ng} / \mathrm{mL})$ \\
\hline 0.5 & $0.11 \pm 0.07(n=10)$ & $0.04 \pm 0.01(n=2)$ \\
1 & $0.16 \pm 0.10(n=12)$ & $0.22 \pm 0.15(n=6)$ \\
2 & $0.34 \pm 0.21(n=51)$ & $0.41 \pm 0.24(n=26)$ \\
3 & $0.54 \pm 0.45(n=36)$ & $0.32 \pm 0.15(n=16)$ \\
4 & $0.85 \pm 0.98(n=78)$ & $0.65 \pm 0.34(n=53)$ \\
\hline
\end{tabular}


a

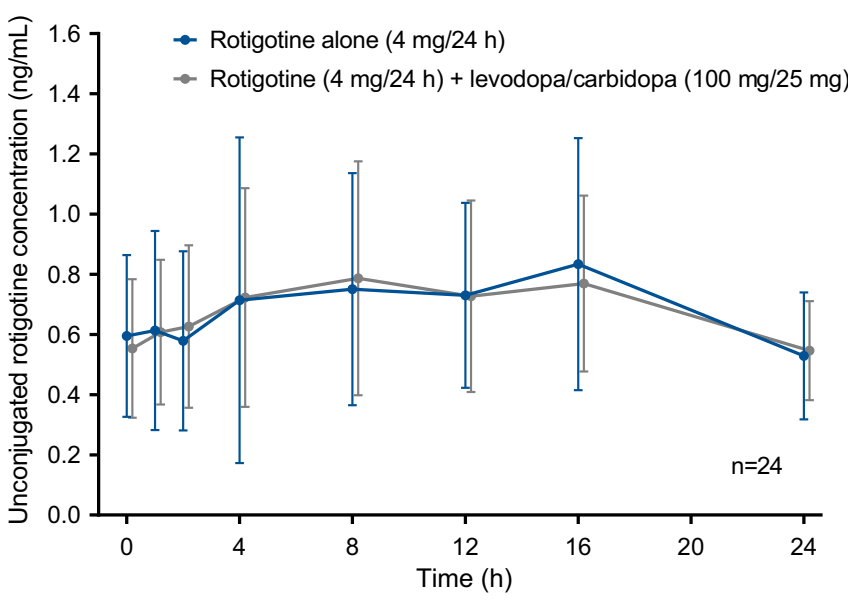

c

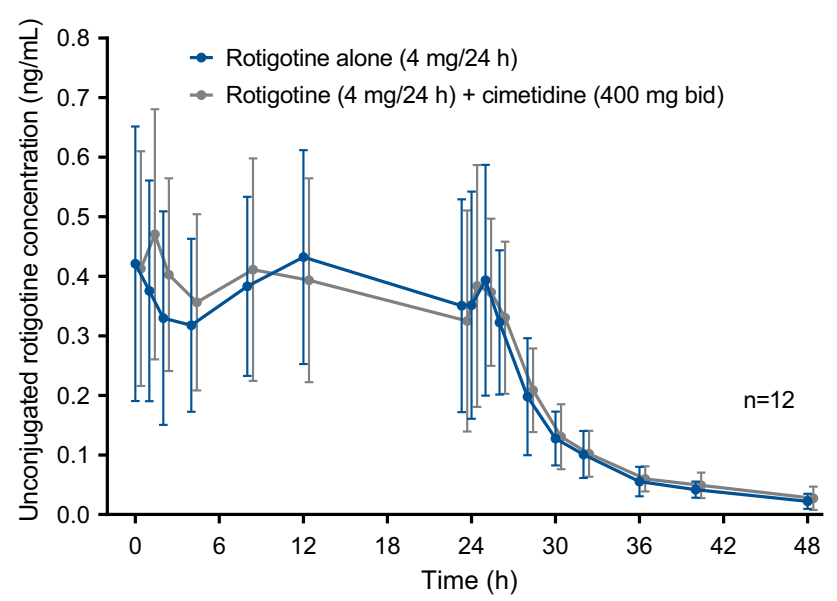

b

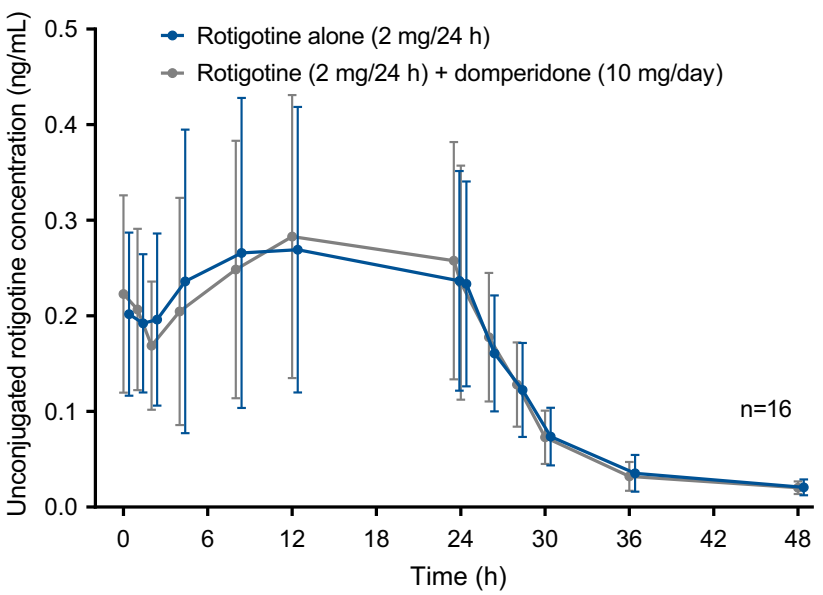

d

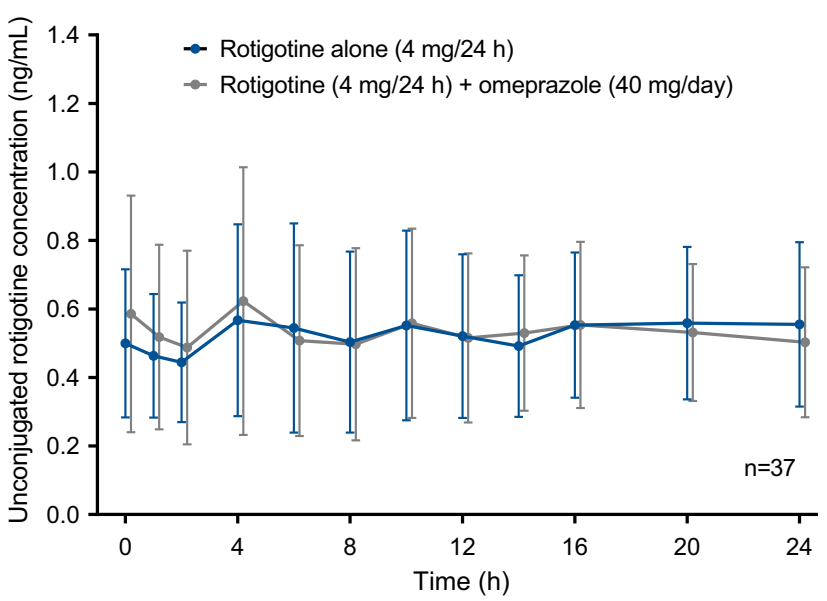

Fig. 6 Mean $( \pm$ SD) steady-state rotigotine plasma concentrations with and without co-administration of a levodopa/carbidopa (100/25 mg) [44], b domperidone (10 mg/day) [45], c cimetidine (400 mg bid), and d omeprazole (40 mg/day) [47]. bid twice daily

unconjugated rotigotine, the mean $C_{\mathrm{max}, \mathrm{ss}}$ and $\mathrm{AUC}_{0-24 \mathrm{~h}, \mathrm{ss}}$ were $0.83 \mathrm{ng} / \mathrm{mL}$ and $15.5 \mathrm{ng} \cdot \mathrm{h} / \mathrm{mL}$ with levodopa/carbidopa, and $0.84 \mathrm{ng} / \mathrm{mL}$ and $15.1 \mathrm{ng} \cdot \mathrm{h} / \mathrm{mL}$ without levodopa/carbidopa. Since the point estimates for the ratio of geometric means (combined vs. monotherapy) for $C_{\text {max,ss }}$ and AUCs for levodopa (1.04, $90 \%$ CI 0.90-1.19; and $0.97,90 \%$ CI $0.92-1.03)$, carbidopa $(1.06,90 \%$ CI $0.97-1.15$; and $1.03,90 \% \mathrm{CI} 0.96-1.12)$, and unconjugated rotigotine $(0.98,90 \% \mathrm{CI} 0.87-1.12$; and $1.02,90 \%$ CI $0.93-1.13$ ) were close to 1 and respective $90 \%$ CIs were within the acceptance range of bioequivalence (0.8-1.25), these data support the use of these two agents without the need for dose adjustments from a pharmacokinetics perspective [44].

\subsubsection{Domperidone}

Like all other dopaminergic therapies, rotigotine activates dopamine receptors in the gastrointestinal tract and the chemoreceptor trigger zone, resulting in gastrointestinal side effects including nausea and vomiting [41, 49-51]. The peripheral dopamine receptor antagonist domperidone stimulates upper gastrointestinal tract motility and has antiemetic effects, and these properties are used to prevent dopaminergic side effects of levodopa and dopamine agonists [49, 52, 53]. It was therefore of importance to demonstrate that domperidone does not influence rotigotine pharmacokinetics since these drugs may be coadministered.

In a two-way crossover study, 16 healthy male subjects (mean age 30 years) received rotigotine transdermal system $(2 \mathrm{mg} / 24 \mathrm{~h}$ over 4 days $)$ alone and in combination with domperidone $(10 \mathrm{mg}$ three times daily $\times 5$ days $)$ [45]. The mean apparent rotigotine dose absorbed was $2.01 \mathrm{mg}$ when given alone, which was similar following concomitant domperidone administration $(2.08 \mathrm{mg})$. Mean steady-state plasma concentration-time profiles of unconjugated rotigotine were similar with and without domperidone (Fig. 6b). The median rotigotine $t_{\max }$ value was $17.8 \mathrm{~h}$ with and without domperidone. Derived 
unconjugated rotigotine pharmacokinetic parameters were not altered in the presence of domperidone: mean $C_{\text {max,ss }}$ and $\mathrm{AUC}_{0-24 \mathrm{~h}, \mathrm{ss}}$ values were $0.26 \mathrm{ng} / \mathrm{mL}$ and $5.15 \mathrm{ng} \cdot \mathrm{h} /$ $\mathrm{mL}$, respectively, with domperidone, and $0.27 \mathrm{ng} / \mathrm{mL}$ and $5.30 \mathrm{ng} \cdot \mathrm{h} / \mathrm{mL}$, respectively, without domperidone. Statistical analysis showed no effect of domperidone on these parameters, as evidenced by the ratio of geometric means for $C_{\text {max,ss }}(0.96,90 \%$ CI $0.86-1.08)$ and $\mathrm{AUC}_{0-24, \mathrm{ss}}(0.97$, $90 \%$ CI $0.87-1.08$ ) close to 1 , and the respective $90 \%$ CIs were within the acceptance range of bioequivalence [45]. Renal clearance of unconjugated rotigotine (mean 0.26 and $0.27 \mathrm{~L} / \mathrm{h}$, respectively) and its metabolites were also similar with and without concomitant domperidone. Hence, no dose adjustments for rotigotine are needed when taken concomitantly with domperidone. Accordingly, domperidone may be used in case of potential gastrointestinal dopaminergic side effects without need for rotigotine dose adjustments.

\subsubsection{Oral Contraceptives}

In a randomized, double-blind, crossover study, 40 healthy women received oral contraceptives $(0.03 \mathrm{mg}$ ethinylestradiol and $0.15 \mathrm{mg}$ levonorgestrel $\times 28$ days) with rotigotine transdermal system $(2 \mathrm{mg} / 24 \mathrm{~h}$ on days $1-3$, then $3 \mathrm{mg} / 24 \mathrm{~h}$ maintenance dose thereafter for a total of 13 days) or placebo [46]. In the luteal phase, mean progesterone serum concentrations were unaffected by coadministration of rotigotine, with observed peak levels of 1.16 and $1.21 \mathrm{ng} / \mathrm{mL}$ following rotigotine and placebo, respectively; progesterone levels were consistently $<2 \mathrm{ng} /$ $\mathrm{mL}$ for all women at all time points during the luteal phase. In addition, no clinically relevant differences in estradiol, luteinizing hormone, and follicle stimulating hormone values were observed following rotigotine and placebo treatments. The concentrations of all four endogenous hormones were adequately suppressed at each time point, suggesting the absence of ovulation with concomitant rotigotine. Presence of rotigotine did not alter the pharmacokinetic metrics of ethinylestradiol and levonorgestrel since geometric mean ratios for $C_{\text {max,ss }}$ and $\mathrm{AUC}_{0-24 \mathrm{~h}, \mathrm{ss}}$, respectively, were as follows: 1.05 (90\% CI 0.93-1.19) and 1.05 (90\% CI 0.9-1.22) for ethinylestradiol, and 1.01 (90 \% CI 0.96-1.06) and 0.98 (90\% CI 0.95-1.01) for levonorgestrel. The oral contraceptive did not change the pharmacokinetic profile of rotigotine; mean plasma concentrations of unconjugated rotigotine were stable throughout day 13 (patch-on period). Derived steady-state pharmacokinetic parameters of unconjugated rotigotine (mean $C_{\text {max,ss }}$ of $0.58 \mathrm{ng} / \mathrm{mL}$ and $\mathrm{AUC}_{0-24 \mathrm{~h}, \mathrm{ss}}$ of $10.62 \mathrm{ng} \cdot \mathrm{h} / \mathrm{mL}$ ) were similar to data in healthy subjects (see above). Overall, rotigotine administered via a transdermal patch $(3 \mathrm{mg} / 24 \mathrm{~h})$ did not impact the pharmacodynamics (i.e., ovulation suppression) or pharmacokinetics of the combined oral contraceptive of ethinylestradiol and levonorgestrel in healthy females, which infers that the contraceptive efficacy of this hormone combination will not be impacted by rotigotine [46].

\subsection{Drug-Drug Interactions Involving the Effect of P450 Enzyme Inhibition}

It was not anticipated that rotigotine has clinically relevant pharmacokinetic interactions with cytochrome P450 (CYP) isoenzyme inhibitors since the major route of rotigotine metabolism is via direct phase 2 conjugation reactions generating the rotigotine $O$-sulphate and rotigotine $O$-glucuronide [31]. Furthermore, the minor rotigotine metabolic pathway is mediated via several cytochrome CYP isoenzymes (1A2, 2C9, 2C19, 2D6, and 3A4; Fig. 2), for which rotigotine has high inhibitory concentrations and inhibitory constants [54], and so the risk for shifts in plasma rotigotine levels due to concomitant use of a CYP450 substrate is less than for a drug which is metabolized solely by one of these isoenzymes. Two drug-drug interaction studies were undertaken to investigate the potential for drug-drug interaction via this pathway (cimetidine: an inhibitor of CYP1A2, CYP2C19, CYP2D6, and CYP3A4; and omeprazole: a CYP2C19 inhibitor). In vitro evaluations with rotigotine (using human microsomes and hepatocytes) suggest a low drug interaction potential with CYP2D6 [54].

\subsubsection{Cimetidine}

In an open, repeated-dose, randomized, two-way crossover study (SP627) of rotigotine $(2 \mathrm{mg} / 24 \mathrm{~h}$ for 2 days, then $4 \mathrm{mg} / 24 \mathrm{~h}$ for 4 days), co-administration of cimetidine (400 mg twice daily for 7 days) did not affect steady-state plasma pharmacokinetics of unconjugated rotigotine in 12 healthy, non-smoking subjects (Fig. 6c) (data on file, UCB Pharma). The geometric mean $C_{\text {max,ss }}$ calculated for rotigotine with and without cimetidine was $0.5 \mathrm{ng} / \mathrm{mL}$. The geometric mean $\mathrm{AUC}_{0-24 \mathrm{~h}, \mathrm{ss}}$ calculated for rotigotine with cimetidine was $8.2 \mathrm{ng} \cdot \mathrm{h} / \mathrm{mL}$ (range $2.0-14.5 \mathrm{ng} \cdot \mathrm{h} / \mathrm{mL}$ ) and without cimetidine was $8.4 \mathrm{ng} \cdot \mathrm{h} / \mathrm{mL}$ (range $2.8-15.5 \mathrm{ng} \cdot \mathrm{h} /$ $\mathrm{mL}$ ). The geometric mean ratio of rotigotine plus cimetidine to rotigotine alone for $C_{\max , \mathrm{ss}}(1.01,90 \% \mathrm{CI}$ $0.90-1.13)$ and $\mathrm{AUC}_{0-24 \mathrm{~h}, \mathrm{ss}}(0.98,90 \%$ CI $0.89-1.07)$ demonstrated that there was no effect of cimetidine coadministration on the extent of the bioavailability of rotigotine. Geometric mean elimination half-lives of rotigotine were also similar without cimetidine $(6.8 \mathrm{~h})$ and with cimetidine $(6.5 \mathrm{~h})$. These data provide evidence that coadministration of the non-specific CYP inhibitor cimetidine had no influence on the pharmacokinetics of rotigotine. 


\subsubsection{Omeprazole}

An open-label, multiple-dose study, evaluated the effect of omeprazole $40 \mathrm{mg}$, a competitive CYP2C19 inhibitor, on the steady-state pharmacokinetics of rotigotine in 37 evaluable healthy Caucasian male subjects (mean age 24 years) [47]. Each subject initially received rotigotine transdermal system ( $2 \mathrm{mg} / 24 \mathrm{~h}$ on days $1-3$ and days $13-14$, followed by $4 \mathrm{mg}$ / $24 \mathrm{~h}$ on days 4-12) followed by concomitant omeprazole treatment (40 mg once daily on days 7-12). All subjects were confirmed to be extensive metabolizers for CYP2C19. Selective inhibition of CYP2C19 by omeprazole did not alter the steady-state plasma pharmacokinetic-time profile (Fig. 6d) or primary pharmacokinetic parameters ( $\mathrm{AUC}_{0-24 \mathrm{~h}, \mathrm{ss}}$ and $C_{\mathrm{max}, \mathrm{ss}}$ ) of unconjugated rotigotine. Mean steady-state concentrations of unconjugated rotigotine ranged from $0.44 \mathrm{ng} / \mathrm{mL} 2 \mathrm{~h}$ post-dosing to $0.57 \mathrm{ng} / \mathrm{mL} 4 \mathrm{~h}$ post-dosing on day 6; similar values were observed on day 12. Mean $C_{\text {max,ss }}$ and $\mathrm{AUC}_{0-24, \mathrm{ss}}$ values were $0.73 \mathrm{ng} / \mathrm{mL}$ and $11.46 \mathrm{ng} \cdot \mathrm{h} / \mathrm{mL}$, respectively, with omeprazole, and $0.69 \mathrm{ng} / \mathrm{mL}$ and $11.63 \mathrm{ng} \cdot \mathrm{h} / \mathrm{mL}$, respectively, without omeprazole. Point estimates for the geometric mean ratios of $C_{\text {max,ss }}$ and $\mathrm{AUC}_{0-24, \mathrm{ss}}$ of unconjugated rotigotine for the comparison rotigotine plus omeprazole versus rotigotine alone were close to 1 (1.06, $90 \%$ CI 0.97-1.16; and 0.99, $90 \%$ CI $0.90-1.08$, respectively). Based on the negligible effect of selective inhibition of CYP2C19 by omeprazole on levels of active unconjugated rotigotine, no rotigotine dose adjustment is advised for patients receiving concomitant omeprazole.

\section{Safety/Tolerability}

The safety of rotigotine transdermal system has been extensively evaluated in patients with early- and advancedstage PD, and RLS. Rotigotine is generally well tolerated, with typical adverse-event (AE) profile characteristics of a dopamine agonist and transdermal administration system. Application site reactions were the most common AEs. Based on data from double-blind, placebo-controlled trials in patients with early- or advanced-stage PD or RLS, approximately one-third (range 15-46\%) of rotigotinetreated patients reported at least one application site reaction compared with 2-21\% of placebo recipients [55]. Most events were of mild to moderate intensity, and the majority of reactions resolved rapidly after removal of the patch [56]. Other common dopaminergic AEs reported in $\geq 5 \%$ of patients included gastrointestinal disturbances (e.g., nausea, vomiting), somnolence, dizziness, and headache. In 6-month clinical trials, premature discontinuation of rotigotine due to AEs occurred in 14-15\% of patients with early PD [51, 57, 58] and $17 \%$ with advanced PD [59]. In 6-month RLS trials, premature discontinuation of rotigotine due to AEs ranged from $15-19 \%[50,60]$. Application site reactions were the AEs most commonly leading to early termination.

Dyskinesia has been reported following long-term rotigotine use in patients with early-stage $\mathrm{PD}$, with an incidence of $17 \%$; however, most cases $(72 \%)$ developed after treatment with levodopa and were potentially due to pulsatile stimulation [61]. Clinically significant augmentation was reported in 39 patients (13\%) with RLS following long-term ( 5 years) rotigotine treatment and led to discontinuation in 12 of 39 (31\%); however, only 15 patients $(5 \%)$ were receiving approved doses $(1-3 \mathrm{mg} / 24 \mathrm{~h})$, suggesting that augmentation following extended treatment is relatively infrequent [62]. As with other dopamine receptor agonists, rotigotine has been associated with impulse control problems and disorders. The incidences of these AEs have yet to be determined [63, 64].

The cardiac safety of rotigotine was evaluated in a phase I, double-blind, randomized, placebo- and moxifloxacin-controlled, parallel-group study (SP864) to assess the potential effects of the rotigotine transdermal system at therapeutic and supratherapeutic doses (titrated to $24 \mathrm{mg} / 24 \mathrm{~h}$ ) on cardiac repolarization [33]. A total of 130 patients with advanced-stage $\mathrm{PD}$ (mean age 63 years) stabilized on levodopa were enrolled and randomized to rotigotine $(n=66)$ or placebo $(n=64)$. Each patient underwent two baseline days with 24-h ECG recording prior to receiving study drugs followed by serial 24-h 12-lead ECGs performed from study days 14 to 43 . As part of the parallel study, each patient assigned to the placebo group was also randomized to receive a 400-mg infusion of moxifloxacin (a known QTprolonging drug) on either day 32 or day 39 and a placebo infusion on the alternate day. Rotigotine-treated patients were given infusions of placebo on both day 32 and day 39 . A total of 126 patients completed the study. Moxifloxacin induced a prolongation of QTc as expected (maximum mean effect of $13.5 \mathrm{~ms}$ ). There was no effect of rotigotine up to supratherapeutic doses on the QTc interval, indicating no association of rotigotine and cardiac repolarization. Rotigotine versus placebo QTc differences in time-matched changes from baseline showed mean effects close to zero (upper confidence limits were below $+5 \mathrm{~ms}$ and lower confidence limits were above $-5 \mathrm{~ms}$ ).

\section{Role of Rotigotine Transdermal System in PD and RLS}

Rotigotine represents the first available transdermally applied drug with proven efficacy as monotherapy for earlystage PD and moderate to severe RLS, and as add-on therapy to levodopa for advanced-stage PD. Five phase III, 
randomized, placebo-controlled trials in patients with early- or advanced-stage PD confirmed that continuously delivered rotigotine led to significant and sustained improvement in symptoms $[41,51,57-59,65]$. The therapeutic effects of rotigotine appeared rapidly (during the titration period) and were largely maintained over the 6-month treatment period in these studies. In two trials of patients with early-stage PD, statistically significant improvement in Unified Parkinson's Disease Rating Scale (UPDRS) scores and clinically relevant increases in responder rates were observed with rotigotine at doses of up to $8 \mathrm{mg} / 24 \mathrm{~h}$, compared with placebo [51, 57, 58]. Furthermore, rotigotine at doses up to $16 \mathrm{mg} / 24 \mathrm{~h}$ significantly reduced 'off' time for patients with advanced-stage PD who were not adequately controlled with levodopa [41, 59, 65]. Significant improvement in early morning motor function and nocturnal sleep disturbances among 287 PD patients with inadequate control of morning motor symptoms has also been demonstrated in a multinational, double-blind, placebo-controlled trial [66]. The long-term safety and efficacy of rotigotine treatment in early PD have been investigated in two open-label extension studies of up to 6 years, in which rotigotine was well tolerated, with more than half of patients remaining on treatment for 4 years or longer [61, 67].

Rotigotine also has proven efficacy as monotherapy for the management of moderate to severe idiopathic RLS, as demonstrated in two phase III, randomized, placebo-controlled trials $[50,60]$. In one clinical trial of 458 patients $(341$ rotigotine $1-3 \mathrm{mg} / 24 \mathrm{~h}$ and 117 placebo), all dosages of rotigotine showed significant improvement in patients' RLS symptoms based on two primary outcome measures (i.e., absolute change from baseline to end of the 6-month maintenance phase in the International Restless Legs Scale sum score and Clinical Global Impression item-1 score) [50]. In a similarly designed trial of 505 evaluable RLS patients, those receiving rotigotine at doses of $2 \mathrm{mg} / 24 \mathrm{~h}$ and $3 \mathrm{mg} / 24 \mathrm{~h}$ had significantly reduced symptoms compared with placebo [60]. In a double-blind, randomized, placebocontrolled, multicenter study, the efficacy of rotigotine transdermal system in 46 patients with moderate to severe idiopathic RLS and periodic limb movement (PLM) in sleep was demonstrated using polysomnography [68]. Specifically, rotigotine-treated patients who received a mean $2.1 \mathrm{mg} / 24 \mathrm{~h}$ maintenance dose had significantly reduced PLM during sleep (i.e., a reduction from $50.9 \mathrm{PLM} / \mathrm{h}$ at baseline to $8.1 \mathrm{PLM} / \mathrm{h}$ at end of maintenance). A long-term, open-label study of extended rotigotine treatment found that rotigotine at optimal doses up to $4 \mathrm{mg} / 24 \mathrm{~h}$ provided sustained efficacy and was generally well tolerated for up to 5 years, with a low incidence of augmentation at licensed doses [62].

\section{Summary}

The extensive investigations of the pharmacokinetics of rotigotine following administration via a transdermal patch permit the following general conclusions: plasma concentration-time profiles and derived pharmacokinetic parameters of rotigotine are similar in healthy subjects, patients with early- or advanced-stage PD, and patients with RLS; dose-proportional pharmacokinetics are observed up to supratherapeutic dose rates $(24 \mathrm{mg} / 24 \mathrm{~h})$ in healthy subjects and target populations; age, sex, and ethnicity do not influence the pharmacokinetic profile of rotigotine in a relevant manner; and dose adjustments are unnecessary in patients with advanced renal insufficiency, including ESRD requiring hemodialysis, and moderate hepatic impairment. Importantly, no clinically relevant drug-drug interactions were observed following co-administration with levodopa/carbidopa, domperidone, or oral contraceptives, as well as cimetidine and omeprazole, thereby demonstrating the absence of an effect by the inhibition of CYP450 metabolism. Also, pharmacodynamics and pharmacokinetics of an oral hormonal contraceptive were not influenced by rotigotine co-administration. These observations, combined with the long-term efficacy, safety, and tolerability of rotigotine, support its use as a continuous non-ergot $\mathrm{D}_{3} / \mathrm{D}_{2} / \mathrm{D}_{1}$ dopamine receptor agonist in the treatment of patients with early- and advanced-stage PD and moderate to severe RLS.

Acknowledgments Author conflicts of interest: Jens-Otto Andreas, Marina Braun, Willi Cawello, and Jan-Peer Elshoff are all employees of UCB Pharma, Monheim am Rhein, Germany. Francois-Xavier Mathy is an employee of UCB Pharma, Braine l'Alleud, Belgium. The authors acknowledge Steve Dobson and Malcolm Darkes (Evidence Scientific Solutions, Horsham, UK) for writing support, which was funded by UCB Pharma SA, Brussels, Belgium.

Open Access This article is distributed under the terms of the Creative Commons Attribution Noncommercial License which permits any noncommercial use, distribution, and reproduction in any medium, provided the original author(s) and the source are credited.

\section{References}

1. de Rijk MC, Tzourio C, Breteler MM, Dartigues JF, Amaducci L, Lopez-Pousa S, et al. Prevalence of parkinsonism and Parkinson's disease in Europe: the EUROPARKINSON Collaborative Study. European Community Concerted Action on the Epidemiology of Parkinson's disease. J Neurol Neurosurg Psychiatry. 1997;62(1):10-5.

2. Van Den Eeden SK, Tanner CM, Bernstein AL, Fross RD, Leimpeter A, Bloch DA, et al. Incidence of Parkinson's disease: variation by age, gender, and race/ethnicity. Am J Epidemiol. 2003;157(11):1015-22.

3. Smith Y, Wichmann T, Factor SA, DeLong MR. Parkinson's disease therapeutics: new developments and challenges since the 
introduction of levodopa. Neuropsychopharmacology. 2012;37 (1):213-46

4. Rascol O, Lozano A, Stern M, Poewe W. Milestones in Parkinson's disease therapeutics. Mov Disord. 2011;26(6):1072-82.

5. Clarke CE. Parkinson's disease. BMJ. 2007;335(7617):441-5.

6. Rao SS, Hofmann LA, Shakil A. Parkinson's disease: diagnosis and treatment. Am Fam Physician. 2006;74(12):2046-54.

7. Jankovic J. Parkinson's disease: clinical features and diagnosis. J Neurol Neurosurg Psychiatry. 2008;79(4):368-76.

8. Ramig LO, Fox C, Sapir S. Speech treatment for Parkinson's disease. Expert Rev Neurother. 2008;8(2):297-309.

9. Simpson J, Lekwuwa G, Crawford T. Predictors of quality of life in people with Parkinson's disease: evidence for both domain specific and general relationships. Disabil Rehabil. 2014;36(23): 1964-70.

10. Duncan GW, Khoo TK, Yarnall AJ, O'Brien JT, Coleman SY, Brooks DJ, et al. Health-related quality of life in early Parkinson's disease: the impact of nonmotor symptoms. Mov Disord. 2014;29(2):195-202.

11. Schrag A, Jahanshahi M, Quinn N. What contributes to quality of life in patients with Parkinson's disease? J Neurol Neurosurg Psychiatry. 2000;69(3):308-12.

12. Hametner E, Seppi K, Poewe W. The clinical spectrum of levodopa-induced motor complications. J Neurol. 2010;257(Suppl 2):S268-75

13. Pedrosa DJ, Timmermann L. Review: management of Parkinson's disease. Neuropsychiatr Dis Treat. 2013;9:321-40.

14. Rodriguez-Oroz MC, Marin C, de Fabregues O. Continuous dopaminergic stimulation: clinical aspects and experimental bases. Neurologist. 2011;17(6 Suppl 1):S30-7.

15. Trenkwalder C, Paulus W. Restless legs syndrome: pathophysiology, clinical presentation and management. Nat Rev Neurol. 2010;6(6):337-46.

16. Berger K, Luedemann J, Trenkwalder C, John U, Kessler C. Sex and the risk of restless legs syndrome in the general population. Arch Intern Med. 2004;164(2):196-202.

17. Allen RP, La Buda MC, Becker P, Earley CJ. Family history study of the restless legs syndrome. Sleep Med. 2002;3(Suppl): S3-7.

18. Winkelman JW. Considering the causes of RLS. Eur J Neurol. 2006;13(Suppl 3):8-14.

19. Garcia-Borreguero D, Williams AM. An update on restless legs syndrome (Willis Ekbom disease): clinical features, pathogenesis and treatment. Curr Opin Neurol. 2014;27:493-501.

20. Garcia-Borreguero D, Allen RP, Kohnen R, Hogl B, Trenkwalder C, Oertel W, et al. Diagnostic standards for dopaminergic augmentation of restless legs syndrome: report from a World Association of Sleep Medicine-International Restless Legs Syndrome Study Group consensus conference at the Max Planck Institute. Sleep Med. 2007;8(5):520-30.

21. Hogl B, Garcia-Borreguero D, Kohnen R, Ferini-Strambi L, Hadjigeorgiou G, Hornyak M, et al. Progressive development of augmentation during long-term treatment with levodopa in restless legs syndrome: results of a prospective multi-center study. J Neurol. 2010;257(2):230-7.

22. Garcia-Borreguero D, Kohnen R, Silber MH, Winkelman JW, Earley CJ, Hogl B, et al. The long-term treatment of restless legs syndrome/Willis-Ekbom disease: evidence-based guidelines and clinical consensus best practice guidance: a report from the International Restless Legs Syndrome Study Group. Sleep Med. 2013;14(7):675-84.

23. Elshoff JP, Braun M, Andreas JO, Middle M, Cawello W. Steadystate plasma concentration profile of transdermal rotigotine: an integrated analysis of three, open-label, randomized, phase I multiple dose studies. Clin Ther. 2012;34(4):966-78.
24. Scheller D, Ullmer C, Berkels R, Gwarek M, Lubbert H. The in vitro receptor profile of rotigotine: a new agent for the treatment of Parkinson's disease. Naunyn Schmiedebergs Arch Pharmacol. 2009;379(1):73-86.

25. Millan M, Maiofiss L, Cussac D, Audinot V, Boutin JA, Newman-Tancredi A. Differential action of antiparkinson agents at multiple classes of monoaminergic receptor. I. A multivariate analysis of the binding profiles of 14 drugs at 21 native and cloned human receptor subtypes. JEPT. 2002;303:791-804.

26. Van der Weide J, Tendijck ME, Tepper PG, De Vries JB, Dubocovich ML, Horn AS. The enantiomers of the D-2 dopamine receptor agonist N-0437 discriminate between pre- and postsynaptic dopamine receptors. Eur J Pharmacol. 1988;146(2-3): 319-26.

27. Van der Weide J, De Vries JB, Tepper PG, Horn AS. Pharmacological profiles of three new, potent and selective dopamine receptor agonists: N-0434, N-0437 and N-0734. Eur J Pharmacol. 1986;125(2):273-82.

28. Timmerman W, Dubocovich ML, Westerink BH, De Vries JB, Tepper PG, Horn AS. The enantiomers of the dopamine agonist N-0437: in vivo and in vitro effects on the release of striatal dopamine. Eur J Pharmacol. 1989;166(1):1-11.

29. Schmidt WJ, Lebsanft H, Heindl M, Gerlach M, Gruenblatt E, Riederer $\mathrm{P}$, et al. Continuous versus pulsatile administration of rotigotine in 6-OHDA-lesioned rats: contralateral rotations and abnormal involuntary movements. J Neural Transm. 2008;115 (10):1385-92.

30. Stockwell KA, Scheller D, Rose S, Jackson MJ, Tayarani-Binazir $\mathrm{K}$, Iravani MM, et al. Continuous administration of rotigotine to MPTP-treated common marmosets enhances anti-parkinsonian activity and reduces dyskinesia induction. Exp Neurol. 2009;219 (2):533-42.

31. Cawello W, Braun M, Boekens H. Absorption, disposition, metabolic fate, and elimination of the dopamine agonist rotigotine in man: administration by intravenous infusion or transdermal delivery. Drug Metab Dispos. 2009;37(10):2055-60.

32. Cawello W, Wolff HM, Meuling WJ, Horstmann R, Braun M. Transdermal administration of radiolabelled [14C]rotigotine by a patch formulation: a mass balance trial. Clin Pharmacokinet. 2007;46(10):851-7.

33. Malik M, Andreas JO, Hnatkova K, Hoeckendorff J, Cawello W, Middle M, et al. Thorough QT/QTc study in patients with advanced Parkinson's disease: cardiac safety of rotigotine. Clin Pharmacol Ther. 2008;84(5):595-603.

34. Babic T, Boothmann B, Polivka J, Rektor I, Boroojerdi B, Hack $\mathrm{HJ}$, et al. Rotigotine transdermal patch enables rapid titration to effective doses in advanced-stage idiopathic Parkinson disease: subanalysis of a parallel group, open-label, dose-escalation study. Clin Neuropharmacol. 2006;29(4):238-42.

35. Cawello W, Kim SR, Braun M, Elshoff JP, Ikeda J, Funaki T. Pharmacokinetics, safety and tolerability of rotigotine transdermal patch in healthy Japanese and Caucasian subjects. Clin Drug Investig. 2014;34(2):95-105.

36. Cawello W, Kim SR, Braun M, Elshoff J-P, Masahiro T, Ikeda J, et al. Pharmacokinetics, safety and tolerability of rotigotine transdermal system in healthy Japanese and Caucasian subjects following multiple dose administration. Eur J Drug Metab Pharmacokinet. 2015 (in press).

37. Kim B-H, Yu K-S, Jang I-J, Soo Lim K, Kim J-R, Elshoff J-P, et al. Pharmacokinetic properties and tolerability of rotigotine transdermal patch after repeated-dose application in healthy Korean volunteers. Clin Ther. 2015 (in press).

38. Cawello W, Fichtner A, Boekens H, Braun M. Influence of hepatic impairment on the pharmacokinetics of the dopamine agonist rotigotine. Eur J Drug Metab Pharmacokinet. 2014;39(3):155-63. 
39. Cawello W, Ahrweiler S, Sulowicz W, Szymczakiewicz-Multanowska A, Braun M. Single dose pharmacokinetics of the transdermal rotigotine patch in patients with impaired renal function. Br J Clin Pharmacol. 2012;73(1):46-54.

40. Cawello W, Elshoff JP, Boekens H, Braun M. Characteristics of rotigotine elimination after patch removal. Eur $\mathrm{J}$ Neurol. 2006;13(Suppl 2):42.

41. Poewe WH, Rascol O, Quinn N, Tolosa E, Oertel WH, Martignoni $\mathrm{E}$, et al. Efficacy of pramipexole and transdermal rotigotine in advanced Parkinson's disease: a double-blind, doubledummy, randomised controlled trial. Lancet Neurol. 2007;6(6): 513-20.

42. Whitesides J, Cawello W, Woltering F, Boroojerdi B, Poewe W. Stable plasma levels of rotigotine following transdermal patch removal and new patch application during long-term treatment of patients with advanced Parkinson's disease. Mov Disord. 2011;26(2):S288.

43. Whitesides J, Cawello W, Braun M, Fichtner A, Oertel WH. Stability of rotigotine plasma levels during long-term transdermal application for patients with idiopathic restless legs syndrome. Mov Disord. 2011;26(2):S365.

44. Braun M, Cawello W, Andreas JO, Boekens H, Horstmann R. Lack of pharmacokinetic interactions between transdermal rotigotine and oral levodopa/carbidopa. J Clin Pharmacol. 2009;49(9):1047-55.

45. Braun M, Cawello W, Boekens H, Horstmann R. Influence of domperidone on pharmacokinetics, safety and tolerability of the dopamine agonist rotigotine. Br J Clin Pharmacol. 2009;67(2): 209-15.

46. Braun M, Elshoff JP, Andreas JO, Muller LI, Horstmann R. Influence of transdermal rotigotine on ovulation suppression by a combined oral contraceptive. Br J Clin Pharmacol. 2009;68(3): 386-94.

47. Elshoff JP, Cawello W, Andreas JO, Braun M. No influence of the CYP2C19-selective inhibitor omeprazole on the pharmacokinetics of the dopamine receptor agonist rotigotine. Clin Pharmacol Drug Devel. 2014;3(3):187-93.

48. European Medicines Agency. Committee for Medicinal Products for Human Use (CHMP). Guideline on the investigation of bioequivalence CPMP/EWP/QWP/1401/98 Rev. 1. 20 January 2010. Available online at URL: http://www.ema.europa.eu/docs/ en_GB/document_library/Scientific_guideline/2010/01/WC5000 70039.pdf. Accessed 27 Feb 2015.

49. Barone JA. Domperidone: a peripherally acting dopamine2-receptor antagonist. Ann Pharmacother. 1999;33(4):429-40.

50. Trenkwalder C, Benes H, Poewe W, Oertel WH, Garcia-Borreguero $\mathrm{D}$, de Weerd $\mathrm{AW}$, et al. Efficacy of rotigotine for treatment of moderate-to-severe restless legs syndrome: a randomised, double-blind, placebo-controlled trial. Lancet Neurol. 2008;7(7):595-604.

51. Watts RL, Jankovic J, Waters C, Rajput A, Boroojerdi B, Rao J. Randomized, blind, controlled trial of transdermal rotigotine in early Parkinson disease. Neurology. 2007;68(4):272-6.

52. Brogden RN, Carmine AA, Heel RC, Speight TM, Avery GS. Domperidone. A review of its pharmacological activity, pharmacokinetics and therapeutic efficacy in the symptomatic treatment of chronic dyspepsia and as an antiemetic. Drugs. 1982;24(5):360-400.

53. Parkes JD. Domperidone and Parkinson's disease. Clin Neuropharmacol. 1986;9(6):517-32.
54. Hansen K, Braun M, Horstmann R, Cawello W, Schaffenecker U. Low drug drug interaction potential of rotigotine. Neurodegenerative Dis. 2007;4(Suppl I):1-350.

55. Boroojerdi B, Wolff HM, Braun M, Scheller DK. Rotigotine transdermal patch for the treatment of Parkinson's disease and restless legs syndrome. Drugs Today (Barc). 2010;46(7): 483-505.

56. Sanford M, Scott LJ. Rotigotine transdermal patch. A review of its use in the treatment of Parkinson's disease. CNS Drugs. 2011;25(8):699-719.

57. Jankovic J, Watts RL, Martin W, Boroojerdi B. Transdermal rotigotine: double-blind, placebo-controlled trial in Parkinson disease. Arch Neurol. 2007;64(5):676-82.

58. Giladi N, Boroojerdi B, Korczyn AD, Burn DJ, Clarke CE, Schapira AH. Rotigotine transdermal patch in early Parkinson's disease: a randomized, double-blind, controlled study versus placebo and ropinirole. Mov Disord. 2007;22(16):2398-404.

59. LeWitt PA, Lyons KE, Pahwa R. Advanced Parkinson disease treated with rotigotine transdermal system: PREFER Study. Neurology. 2007;68(16):1262-7.

60. Hening WA, Allen RP, Ondo WG, Walters AS, Winkelman JW, Becker P, et al. Rotigotine improves restless legs syndrome: a 6-month randomized, double-blind, placebo-controlled trial in the United States. Mov Disord. 2010;25(11):1675-83.

61. Giladi N, Boroojerdi B, Surmann E. The safety and tolerability of rotigotine transdermal system over a 6-year period in patients with early-stage Parkinson's disease. J Neural Transm. 2013;120(9):1321-9.

62. Oertel W, Trenkwalder C, Benes H, Ferini-Strambi L, Hogl B, Poewe $\mathrm{W}$, et al. Long-term safety and efficacy of rotigotine transdermal patch for moderate-to-severe idiopathic restless legs syndrome: a 5-year open-label extension study. Lancet Neurol. 2011;10(8):710-20.

63. Schreglmann SR, Gantenbein AR, Eisele G, Baumann CR. Transdermal rotigotine causes impulse control disorders in patients with restless legs syndrome. Parkinsonism Relat Disord. 2012;18(2):207-9.

64. Hinnell C, Hulse N, Martin A, Samuel M. Hypersexuality and compulsive over-eating associated with transdermal dopamine agonist therapy. Parkinsonism Relat Disord. 2011;17(4):295-6.

65. Nicholas AP, et al. A randomized study of rotigotine dose response on 'off' time in advanced Parkinson's disease. J Parkinsons Dis. 2014;4:361-73.

66. Trenkwalder C, Kies B, Rudzinska M, Fine J, Nikl J, Honczarenko $\mathrm{K}$, et al. Rotigotine effects on early morning motor function and sleep in Parkinson's disease: a double-blind, randomized, placebo-controlled study (RECOVER). Mov Disord. 2011;26(1):90-9.

67. Elmer LW, Surmann E, Boroojerdi B, Jankovic J. Long-term safety and tolerability of rotigotine transdermal system in patients with early-stage idiopathic Parkinson's disease: a prospective, open-label extension study. Parkinsonism Relat Disord. 2012;18(5):488-93.

68. Oertel WH, Benes H, Garcia-Borreguero D, Hogl B, Poewe W, Montagna $\mathrm{P}$, et al. Rotigotine transdermal patch in moderate to severe idiopathic restless legs syndrome: a randomized, placebocontrolled polysomnographic study. Sleep Med. 2010;11(9): 848-56. 